Please cite as: Geelan, D., Christie, P., Mills, M., Keddie, A., Renshaw, P. and Monk, S. (2015). Journal of Pedagogies and Learning, 10(1), 13-23 DOI: 10.1080/22040552.2015.1084673

\title{
Lessons from Alison: a narrative study of differentiation in classroom teaching
}

David Geelan, Pam Christie, Martin Mills , Amanda Keddie, Peter Renshaw and Sue Monk

ABSTRACT Teaching is challenging in part because, although school structures are to some extent modelled on industrial approaches in which the 'raw materials' are assumed to be very similar, human beings are endlessly diverse. Understanding the many differences amongst students, and treating these differences as teaching resources rather than deficits, is a powerful approach. This paper draws on teacher interviews and classroom observations collected during a two-year study of two regional Queensland schools to explore issues of 'recognition', 'distribution' and social justice. It uses narrative vignettes from a single classroom to provide an occasion for reflection on the part of the reader on how schooling can better meet the needs of students, and outlines six pedagogical practices for effective classroom teaching.

KEYWORDS Narrative; differentiation; classroom; recognition

After the glare of the north Queensland sun, stepping into the cool darkness of the verandah is a recipe for sudden blindness. A moment to adjust, and we're in the midst of a swirling group of Year 8 students who look at us curiously. A couple ask why we're here, but as we're about to answer Alison ${ }^{1}$ steps out of her classroom. It takes a moment for them to notice her, but once they do the swirl starts to condense into two more or less straight lines. There's still some loud conversation and a bit of pushing towards the back of the line, and Alison starts to count, quietly, but projecting her voice down the verandah: “ $5,4,3, \ldots$ " The condensation speeds up, and she doesn't need to finish the countdown. The lines are silent, watching her ... and us. She invites the students into the classroom, and they file in. In some of the other classrooms we've observed on this trip, it took several minutes to quiet the class outside the room, and then they erupted again inside and took several more minutes. It wasn't unusual for students to actually start learning $10 \mathrm{~min}$ after the bell. Not here, though: the students talk to one another quietly, but file to their desks and get out their books and pencil cases, and are ready to learn within a minute.

\footnotetext{
${ }^{1}$ All names used in the paper, aside from those of the authors, are pseudonyms.
} 
We're in Alison's classroom as part of a research study on two schools in a small city in regional Queensland, Australia. Our mission in this particular project is not so much to focus on enhancing teaching for all students, although that would be a nice side effect. Rather, we think about it as finding ways to specifically enhance the experience of school and the level of success for disadvantaged students.

But that's not quite it either. We're focused on the issue of 'difference' in the classroom. It's a truism that 'every student is different', but the notion of difference plays out in all sorts of ways. Teachers (and administrators, parents and students) tend to think of students as being on a continuum of academic ability from the least to the most capable, for example. Often there's an associated recognition that students have different abilities in different subject areas, and may have certain learning difficulties or talents as well. There are a huge number of possible dimensions of difference beyond the academic, of course - differences of race, sex, gender, wealth and poverty, family and social background, learning styles and multiple intelligences and so on. The members of our research team try to think of these as useful ways of thinking about difference, rather than as immutable, reified characteristics of students.

There is often talk of 'differentiated instruction' - different teaching and different tasks for different students. It's a nice idea and a necessary one, but there are two problems with it: (1) It is very difficult for any teacher to 'do enough': maybe there can be two different activities, maybe even three, but if it's true that 'every student is different' then there's always more to do. (2) Differentiation is usually imagined in terms of compensating for 'deficits' on the part of the students. Not always - there's recognition of differentiation for the gifted and talented, for example - but often it's thought of as 'these are the problems with the students - here are my solutions'. It goes even deeper than that, though. If the teacher always gives little Johnny the 'easier', lower level work throughout his school career, his opportunities in later life will be restricted. He may not be able to have as broad a choice of possible occupations as his actual abilities would have offered. These are real tensions, and are not simple to address: failing to achieve on more difficult tasks all the way through school would have been similarly unhelpful to little Johnny.

One key focus of our study is to look at how teachers can draw on difference as a resource in the classroom, rather than seeing difference as a set of deficits to be overcome. That is, saying 'every student is different' needn't necessarily be a source of guilt and stress on the part of teachers who feel that they can never really do enough. It can also be a very positive thing in that the classroom is full of students with different knowledge, life experience, skills, interests and even ways of viewing the world. There are ways to draw on and attend to those differences that mean students can 
contribute to each other's learning in rich ways. There's an underlying issue in that last sentence, which is that seeing the classroom as more of a collaborative learning space, in which students learn from each other as well as from the teacher, can also help to share the load and enhance the ability of the classroom to meet the needs of every student. The teacher is still the director; still the one ultimately responsible for what goes on in the classroom, but considering the students as an educational resource much more than is typically the case is one way of addressing difference in a positive way.

To return to little Johnny for a moment (and please do mentally extend this to think about the differences of little Jane, Abdul, Mandurway, Tarquin, Kimiko and the rest of their classmates), Fraser $(1995,1997)$ has developed a theoretical approach to justice that might help to unpack some of the issues a little more deeply. There are issues of recognition of difference - of not submerging students' differences in a dominant mainstream approach to schooling. Some of the best-intentioned teachers can run into trouble with this, when they define equity as 'I treat every student exactly the same'. It's a good aspiration, but what it typically ends up meaning in practice (though not always) is 'I treat every student like a white, straight, middle class person'. Yet clearly there are black, gay, poor students ... and black, straight, wealthy students, and brown, androgynous, middle class students ... a whole rainbow of possibilities. Recognising difference doesn't and shouldn't mean suppressing the mainstream, but it also shouldn't mean suppressing everyone to fit the mainstream. It means honouring all identities, cultures, traditions and other features of difference.

Part of the challenge that Fraser recognised is that the 'recognition' dimension is necessary but not sufficient, and in fact if carried to extremes can be counterproductive. Poorer students typically do less well in school and have less successful (in terms of their own happiness, longevity, comfort and so on) outcomes than other students. 'Recognition' that they come from poor backgrounds shouldn't result in the kinds of programmes and approaches that perpetuate that poverty. Little Johnny shouldn't be left unchallenged to do well because of his background.

So a complementary dimension is that of distribution, which focuses on equity. There are very large inequities in society in terms of the ways certain goods (not only material) are distributed, and those inequities are not inevitable, and are usually not the fault of those who become their victims. In brief, little Johnny didn't decide which side of the tracks to be born. Distribution needs to be held in tension with recognition: any approach to distribution that achieves its goals by submerging the identities of the students ('treating them all the same') has problems, but any response to recognition that perpetuates existing disadvantages similarly has problems. Seeking real, practical ways through these complex dilemmas - ways that actually change what Ms. Knightsbridge does in her classroom on 
Monday mornings and Friday afternoons - is what we're about. It's not easy, but we think it's worthwhile.

Alison walks across the back of the room and down the far aisle, checking students' desks. She notices one student doesn't have a pen, asks him about it and loans him one from her collection when he says he forgot to bring it. This lesson continues from one - on the topic of weather and weather maps with the same class before lunch, and Alison begins by eliciting some of the key concepts from the class, working from a large diagram she left on the blackboard. The lesson is very explicitly linked to the previous lesson, and students' learning is 'joined-up' in a way that makes it clear that there are goals and connections between lessons and across the topic.

This class is a 'low stream' Year 8 group: the school 'streams' students into classes based on their scores on literacy tests and this is considered to be one of the more difficult classes, both in terms of the diversity of student needs and academic levels and of the behavioural challenges experienced by several students. We have been observing the same group of students with multiple teachers, and have seen very different approaches taken, with very different results in terms of classroom climate and level of learning achieved.

Alison uses a 'gold slip' system for rewarding good behaviour and achievement in class. This is a schoolwide system with rewards available, but is used to varying degrees and in a variety of different ways by different teachers. Alison has written today's focus - 'behaviours' - on the board, and is explicitly focusing on 'catching them being (and doing) good'. On other days and in other lessons, there are other foci such as 'bringing equipment', 'learning', 'kindness' and more, and these are explicitly alluded to in the lessons. Explicit expectations - in terms both of behaviour and learning - are a strong feature of Alison's teaching.

This paper is written in a variety of modes and voices - narrative, explanatory, theoretical. It has several authors with different perspectives, views and approaches. The choice to write it in this way is conscious and intentional. It is chosen in order to provide an 'occasion for reflection' (Geelan, 1997) on the part of you, the reader. We have chosen a narrative method (Clandinin \& Connelly, 1996; Geelan, 2003), incorporating 'impressionistic tales of the field' (van Maanen, 1988), for this particular facet of a larger research project - because we feel that it is most able to capture something of the richness, complexity and human quality of school life. Theories, however complex, must simplify life by abstracting some facets and ignoring others. Stories, too, highlight some facets and hide others a process of selection is involved. We believe, however, that stories, through allusion and shading and other techniques used in fiction, can capture facets, faces and voices in classrooms that are missed by theories and the practices of theory building. We argue that stories and impressionistic tales are 
valuable as planks of a research methodology for what they show us, but that their use must be accompanied by a critical consciousness of what they hide.

John van Maanen (1995) has referred to reading as 'the third moment of ethnography', where the first moment is fieldwork and the second is writing. The fieldwork for this study was conducted in two schools in northern Queensland - and some of the processing occurred over beers and glasses of wine in the afternoon after school - and the writing in various offices in Australia and South Africa. The reading, we hope, is taking place around the world, and the goal is to connect the things we saw and heard and thought in this classroom with the things you know.

If you are a teacher (or used to be), one test of whether we have been successful in our intentions is the little 'uhuh' noise of recognition we have seen other teachers make when they read our accounts of classrooms (Geelan, 2003). We could refer to this as 'verisimilitude' - seeming true. Since you were not in the classroom with us, you have no means of testing whether our account is in fact a true account of what happened. We might, for reasons and agendas of our own, seek to intentionally highlight some features or incidents, and 'hush up' others. Alternatively, our own assumptions and experiences may simply have blinded us to some of the things happening in the classroom, so that even with the most honest intentions our account might not be finally, objectively 'true'. For our purposes, though, perhaps 'seeming true' is sufficient: if teachers recognise this classroom as 'feeling like' a real classroom, then it can serve as an occasion for reflection - a chance to think about teachers and teaching. And perhaps that's enough.

"Cameron, if you saw this weather map here, and you were planning to go fishing on the weekend, what might you do?" Cameron stops doodling in the edge of his page and looks up, to where Alison is pointing to the map on the board. The town we're in is clearly marked, and a cold front is bearing down on it from the west. "Um ... I might ... I dunno Miss." Alison waits a moment, then prompts him: "What kinds of bumps are on this line?" "Pointy ones." "Right. What kind of front is that?" Cameron continues to frown for a moment, then grins and looks around at the other students. It's clear he doesn't know the answer, and even a prompt to check back in his notes seems not to be eliciting the required information, but Alison doesn't move to another student. Instead she continues to work with Cameron until he understands - and so do the other students - that it's a cold front and perhaps he should postpone the fishing trip until the forecast is more promising.

Alison assigns the students a worksheet that further extends the topic, and walks quietly around the room, checking students' work and helping out or redirecting as required. There's a low buzz of conversation, but most of it seems to be on topic, and it's low enough that the cicadas in the trees outside are the main soundtrack to the lesson. Discipline for any annoying or inappropriate behaviour 
is swift and emphatic, but not hostile, and the overall class climate is one of mutual respect and, yes, affection, from teacher to students and reciprocally. One student is 'sinbinned' out on the verandah for two minutes, and returns, chastened, and continues with his work. Another is threatened with, but not sent to, the office.

It's not that behaviour management is easy with these students, or that the behavioural problems aren't there, but they are managed professionally and immediately, and - crucially - without being allowed to interrupt the flow of learning, for the misbehaving student or the rest of the class. This is behaviour management in the service of learning, not control for its own sake.

We sought and gained permission to conduct this study from Education Queensland, the state education department responsible for these two government schools, and from the school principals. The study was approved and supervised by the University of Queensland Research Ethics Committee. Alison and all the other teachers we spoke to and observed had been informed about the study and signed consent forms to participate, in the knowledge that they were free to leave the study at any time and have data collected from and about them removed. All students who were interviewed or participated in focus groups received parental consent to participate in the form of signed consent forms. It is not legally required to obtain signatures from minors where parental signatures have been obtained, however as a courtesy to student participants they were included only if they had signed. Some of the students in the classrooms observed would not have returned signed parental consent forms. The classroom observations focused on the teachers and the ways in which they behaved and the students responded, and any descriptions of specific students' behaviour were drawn from students who had given their own and obtained parental consent.

Asked about teaching more challenging students in one of the places she worked, Alison says: You have to become very open-minded. You have to just accept the kids for what they are. You couldn't judge them from my background, because when you first go there, you think 'Oh God, how am I going to handle this?! They're awful, they don't respect each other, they swear, they fight.' And then you have to start looking at the reality that this is what the kids believe. They really respect you if you respect them, and if you're open-minded about their background, and the things that they think are important. So when you teach, you constantly go back to saying "This is what you might do in your society" - how relationships are between people. "And in history, this is what it's like" - constantly go back and forwards to give them something to be able to compare.

In some other classrooms we visited, a continuous part of the soundtrack was students drumming on their desks with pens, rulers or hands, and teachers correcting that behaviour, with increasing frustration and limited success. In those rooms it was often difficult for us to focus on what the 
teachers and students were saying, and it seems plausible that it would be similarly difficult for some students to pay attention - particularly those with any level of reduced hearing. In Alison's classroom, there's virtually no drumming - one student begins and then immediately stops himself, without any intervention from Alison. It's only speculation, but it seems likely that this is just one of the many expectations that Alison has intentionally, explicitly set in place throughout the year, and that now the drumming is perceptible only by its absence.

Narrative methods in qualitative research exist in the tension between the tales we live and the tales we tell. The two kinds of tales are very different, but share a common narrative nature. They share a dynamic relationship, where lived tales are influenced by told tales, and vice versa. In research, the telling of tales is a means of abstracting something about a concrete but complex situation - the lived tales of teachers and students in classrooms, cradled within the lived tales of administrators and governments and the whole community. But if the tales are only taken out, the research activity has failed. The told tales should echo back into the lives of teachers and students in classrooms - and into our own lives and practices - and change them. That's why we do what we do as qualitative researchers who use narrative methods.

Lieblich, Tuval-Mashiach, and Zilber (1998) have written a very useful review of the literature and guide to using narrative methods in psychology. They describe a scheme of four different ways of 'reading' narrative research materials, especially autobiographical narratives. These are the holisticcontent, holistic-form, categorical-content and categorical-form readings. They depend on whether the reader's focus is predominantly on the content or on the form of the tale, and on whether the reading is categorical (i.e. attempts to place either the form or the content of the narrative into a predeveloped or emergent category system) or holistic (i.e. attempts to attend to the narrative as a whole). Their work is intriguing in its own right, and as a disciplined treatment of ways of reading narratives. This is a facet that is ignored by many narrative researchers, or rather, the assumption seems to be that a holistic reading, and particularly one that connects with the reader's own experience, is the only possible reading of research narratives. While we have taken Lieblich et al. (1998) scheme as a reminder to attend to research texts in a number of ways, we have not used it as an explicit part of our analysis of these tales, because we think it does pay too little attention to the role of the reader's own teaching experience and to the connections made through allusion and resonance: essentially, their approach seems to be too analytic and dry, and to take the relationship of text and reader as being too coldly rational.

Clandinin and Connelly $(1995,1996,2000$; Connelly \& Clandinin, 1988, 1994) have worked in the field of narrative for many years, and written a number of books outlining their approach to 'narrative 
inquiry'. The notion discussed above - that life itself, including the life in schools, is made up of 'lived stories', and that narrative inquiry is the process of creating written stories that in some way capture these lived stories - owes much to their work.

The larger study of which this paper is one of the products was a design-based study (Design-based Research Collective, 2003) conducted by the team of authors of this paper in 2010-2012. Most or all of the team stayed for up to a week at a time, usually 3-4 visits per school year, in the northern Queensland town in which the two schools that agreed to participate in the study were situated, and spent each day in the school. Teachers, students, administrators and support staff were interviewed, and lessons observed. These schools had some similarities and differences, but both served catchments with a wide range of socioeconomic status represented and had significant Aboriginal and Torres Strait Islander populations.

The study was design-based in approach, and used (as has been discussed) narrative as both a methodology and a mode of representation. That is to say, narratives of practice and of their lives were elicited from students and teachers in interviews, and narratives are also being used to richly portray the research outcomes. The design-based facet of the study involved working alongside smaller groups of teachers in each school to seek to implement strategies to better address student differences, and will be reported in other papers. This one is focused on an earlier phase of the study in which multiple classrooms were visited and classroom observations written by researchers and linked with interviews with the participating teachers.

The specific case of one lesson with one teacher, Alison, reflects many of the positive things we saw in many classrooms, but also forms a contrast with some of the less effective approaches we also observed. Written narrative accounts of the kind included here are intended to provide an occasion for reflection on the part of the writer and the reader: if the tales are written well, particular dilemmas of education are seen with their full moral and emotional force, and much of their complexity, intact. Such dilemmas, suggest Clandinin and Connelly in their 1995 book 'Teachers' Professional Knowledge Landscapes', arise out of the richness and complexity of the 'professional landscape' within which teachers work. This goes beyond the classroom context to include the other 'professional places' within the school, such as staff rooms and offices, and to include the life experiences and values of teachers. The professional landscape also includes 'the conduit' (Clandinin \& Connelly, 1995, p. 9) or 'the pipe' through which flow the apparently unassailable theoretical pronouncements of researchers and the prescriptions of governmental and educational authorities. Such prescriptions have a moral force, because the descriptive 'is' of research tends to become the prescriptive 'ought' of 
accountability and requirement. Clandinin and Connelly describe these intrusions from the conduit as 'sacred stories'.

Teachers in classrooms are, in a sense, in a secret environment. Although they are increasingly accountable to parents and administrators, and although the 'conduit' has a strong influence on what occurs, essentially the way teachers act and think in the classroom is private. The stories they enact in this context are their actual classroom practices, and reflect their biographies as teachers and learners and their beliefs and values about teaching (and life). The gap between these 'secret stories' and the 'sacred stories' of the school is another - although perhaps rather richer - description for the oft lamented 'theory-practice gap'. Teachers tell and share their secret stories when it is safe to do so sometimes in the staffroom and with other teachers, sometimes (if they're very fortunate) with their partners at home. Secret stories, though, do not play well in the professional landscape outside the classroom, because by necessity they present the teacher as tentative, thoughtful and uncertain. In the professional landscape, it is necessary for teachers to appear confident, competent, certain - so teachers also tell 'cover stories' which deal with classroom events, but present the teachers' roles and actions as unproblematic.

Alison is in constant movement: she stops to correct behaviour or help a student, but such visits tend to be brief prompts rather than long explanations. In other classrooms we had seen teachers spend 20 min or more working with a single student, while the remainder of the class was largely off task and unproductive. Sooner than we would have expected, it's time to debrief the activity and answer the questions: an activity that might have filled a 70-min class period in other classrooms is only a third of what is planned, and achieved, in this lesson.

"All right, let's go through those questions." This announcement from Alison doesn't noticeably diminish the underlying hum of conversation, so she begins counting backward from five. It takes until one this time, but she gets silence. Each question is discussed explicitly and in detail, with clear information about exactly what ideas would constitute a full answer. Answers are elicited from students, built on and polished, and the standards for quality are very explicit. Rather than simply giving the answers, Alison clarifies what each question was asking. The questions themselves are not simply about recalling information from the previous lesson, or comprehending new text resources, but involve synthesis, application and evaluation of concepts from the earlier lesson.

Alison's own biography as a teacher is fascinating, and may help to explain her excellent skills. She has taught at both primary and secondary levels, and in a variety of contexts in different urban and rural areas of Queensland. She says: 
"I do often have the lower level Literacy classes, because if you've got the primary/secondary, you always end up getting the classes with the lowest Literacy level - because you tend to teach more like a primary school teacher. The primary background has helped enormously, because that's when I learned to teach. It's absolutely true - primary school teachers know how to teach. And you can see the difference in the high school classes, particularly for Grade 8s. When the kids come in, they're used to primary school. They're used to having all this scaffolding and support, and they still want that. So the kids that are struggling in the class will work a lot better if you can show them that you're there to help them. If that becomes a nurturing type of experience, and I do tend to work better with the kids that are really struggling, I tend to get a lot more out of them in my classes. We start with a paragraph in the first semester, a piece of assessment. By the end of the year, you've got a page and a half piece of assessment."

"Cassie, what is the weather going to be like in Victoria this week, according to this weather map?" "Um ... where's Victoria?" Alison checks and discovers that a number of students don't have a clear idea of where the Australian states are located, so she quickly draws a map of Australia on the board and works with the class to identify the locations of the states, directing questions to students by name to check their understanding. With this 'just in time' remediation completed, Alison finalises the discussion of the questions, and asks "Who got how many right?", counting down from all correct as students lower their hands. She assigns the next task to the majority of the students and spends a few moments working with the students who answered least questions correctly, helping them to find the correct answers and explaining the concepts about which the students are confused.

One thing that struck the research team in observing lessons in a large number of classrooms was how much time students spend in class not learning. In particular, the students who finish their work first spend huge amounts of time sitting around waiting for the teacher to dispense the next task or piece of information. Is it surprising they sometimes misbehave? We (as researchers) were bored and fidgety!

Many factors contribute to this issue, from poorly behaved students who require a lot of teacher time to students with reading levels 5 or more years below their grade levels. It also relates to the way we 'do school' (Anstey \& Bull, 1996), though, in that students aren't given autonomy to continue with other work or move ahead but required to wait on the 'drip feed' from the teacher.

"All right everyone, too much negative energy!" The comment comes from a student as the noise level in the classroom rises a little, but the laughs and smiles and knowing looks give us the clue that this is a frequent statement used by Alison in her classroom. 
Six themes emerged from observing a large number of classrooms in a study of two schools in regional Queensland, and were exemplified in Alison's teaching:

1) forward momentum - not rush, but in the best lessons there is a drive towards the next thing to be done and learned, rather than a sense of aimlessness. The students know there'll be something along soon so they'd better get on with it.

2) explicit expectations - in the best lessons there's no 'do this, but I won't tell you why' or 'guess what's in my head, and if you get it wrong I'll yell at you' (Anstey \& Bull, 1996). What the teacher expects - both in terms of behaviour and learning - is made clear and explicit for the students.

3) focus on learning - it is ironic how easy it is, in school, to lose focus on the learning. There are so many other activities involved in 'doing school' (Anstey \& Bull, 1996) that sometimes learning slips off the radar. In the best lessons, it's clear that students are here to learn, and that the teacher knows what is to be learned and how to check that it has been.

4) behaviour management in the service of learning - this is a similar point, but an important one. The management of behaviour - what used to be called 'discipline' - is a not a goal in itself. Behaviour is managed in the service of learning, and this principle will change the ways in which that happens. Of course, learning to behave well and do the right thing is also important, but it can't be the main goal in the classroom.

5) engaging the disengaged - some of the students make the choice not to work. In the best classes, they don't get away with it. As a young teacher, David Geelan used to struggle with this one, because he was all about allowing students to choose... but (some) adolescents aren't mature enough to make good decisions. The teachers who are aware of what everyone is doing and can gently engage the disengaged students are the ones who are meeting the goal of challenging all students to succeed.

6) enhancing autonomy - students have very little choice about what happens in school. That includes both the rules in the classroom and what (and how) they'll learn. Most of the examples of student autonomy offered when we interviewed students were things like whether or not they were allowed to have music playing in the room while they work. Deeper forms of autonomy where they make real choices about how to learn would actually also help maintain forward momentum. (And this point doesn't really contradict the previous one: they need scaffolding and support to make good decisions.)

Identifying these elements may be seen as simply stating the obvious - and in many ways it is. And yet, in many of the classrooms we observed, these elements of teaching were vitiated in various ways. Clearly that is a far more complex matter than simply blaming the teachers: a complex constellation 
of factors including features of the way schooling is done in Australia, students' backgrounds, social capital and past experiences with learning and an enormous range of other factors is relevant.

Working through the answers to the final activity, the word 'tic(k)' comes up in the discussion, and Alison seizes the opportunity to ask "What is the other meaning of that word, other than the parasite?" After eliciting the idea of a ticking clock, a student comes up with the notion of facial tics and now all the students have a new term in their vocabularies. This is just one example of a number of simple, incidental, low-key opportunities during the lesson that Alison seized upon to engage the class in incidental learning.

Dufur, Parcel, and Troutman (2010) measured the relative effects on student achievement of social capital gained at home compared with that gained at school. While they found that social capital from the home was a greater influence on achievement, the contribution from the school was far from negligible. The social capital notion is a powerful and important one, but one of the ways in which it seems to play out is as an excuse for less equitable outcomes - a way of explaining away the lower achievement of disadvantaged students as being an effect of the differences (perceived as deficits) in their social capital sourced at home. The finding that the school also has an important role in building students' social capital is valuable in throwing attention back onto the dimensions of student development that are within the control of the school. Achievement in the classes taught by the most effective teachers can be advanced by several months each school year compared to the average ... and that in those taught by less effective teachers can be delayed by similar margins (e.g. Gordon, Kane, \& Staiger, 2006). The goal here is, of course, not to blame teachers when their students are not achieving, but to share simple, effective approaches drawn from the professional work of effective teachers, that will enhance the effectiveness of all teachers. We would argue that good teaching for students from disadvantaged backgrounds is simply good teaching - but that given the other challenges facing these students, good teaching is even more crucial for them than for other students.

Funding This work was supported by an Australian Research Council Discovery Project Grant [grant number DP109382].

\section{References}

Anstey, M., \& Bull, G. (1996). Re-examining pedagogical knowledge and classroom practice. In G. Bull \& M. Anstey (Eds.), The literacy lexicon (pp. 89-106). Sydney: Prentice-Hall.

Clandinin, D. J., \& Connelly, F. M. (2000). Narrative inquiry: Experience and story in qualitative research. San Francisco, CA: Jossey-Bass. International Journal of Pedagogies and Learning 23 
Clandinin, J., \& Connelly, F. M. (1996). Teachers' professional knowledge landscapes: Teacher stories - stories of teachers - school stories - stories of schools. Educational Researcher, 25, 24-30.

Clandinin, D. J., \& Connelly, F. M. (1995). Teachers' professional knowledge landscapes. New York, NY: Teachers College Press.

Connelly, F. M., \& Clandinin, D. J. (1994). Telling teaching stories. Teacher Education Quarterly, 21, 145-158.

Connelly, F. M., \& Clandinin, D. J. (1988). Teachers as curriculum planners: Narratives of experience. New York, NY: Teachers College Press.

Design-based Research Collective. (2003). Design-based research: An emerging paradigm for educational inquiry. Educational Researcher, 32, 5-8.

Dufur, M. J., Parcel, T. L., \& Troutman, K. P. (2010). Does capital at home matter more than capital at school?: Social capital effects on academic achievement. Research in Social Stratification and Mobility, 31, 1-21. doi:10.1016/j.rssm.2012.08.002

Fraser, N. (1995). From redistribution to recognition: Dilemmas of justice in a 'post-socialist' age. New Left Review, 212, 68-93.

Fraser, N. (1997). Justice interruptus: Critical reflections on the 'postsocialist' condition. New York, NY: Routledge.

Geelan, D. R. (1997). Weaving narrative nets to capture school science classrooms. Research in Science Education, 27, 553-563.

Geelan, D. (2003). Weaving narrative nets to capture classrooms: Multimethod qualitative approaches for educational research. Dordrecht: Springer.

Gordon, R. J., Kane, T. J., \& Staiger, D. (2006). Identifying effective teachers using performance on the job. In J. Furman \& J. Bordoff (Eds.), Path to prosperity: Hamilton project ideas on income security, education and taxes (pp. 189-226). Washington, DC: Brookings Institution Press.

Lieblich, A., Tuval-Mashiach, R., \& Zilber, T. (1998). Narrative inquiry: Reading, analysis and interpretation. Thousand Oaks, CA: Sage.

van Maanen, J. (1988). Tales of the field: On writing ethnography. Chicago, IL: The University of Chicago Press.

van Maanen, J. (1995). An end to innocence: The ethnography of ethnography. In J. van Maanen (Ed.), Representation in ethnography (pp. 1-35). Thousand Oaks, CA: Sage. 